\title{
What is a smart device? - a conceptualisation within the paradigm of the internet of things
}

\author{
Manuel Silverio-Fernández ${ }^{*}$, Suresh Renukappa and Subashini Suresh
}

\begin{abstract}
The Internet of Things (IOT) is an interconnected network of objects which range from simple sensors to smartphones and tablets; it is a relatively novel paradigm that has been rapidly gaining ground in the scenario of modern wireless telecommunications with an expected growth of 25 to 50 billion of connected devices for 2020 Due to the recent rise of this paradigm, authors across the literature use inconsistent terms to address the devices present in the loT, such as mobile device, smart device, mobile technologies or mobile smart device. Based on the existing literature, this paper chooses the term smart device as a starting point towards the development of an appropriate definition for the devices present in the loT. This investigation aims at exploring the concept and main features of smart devices as well as their role in the loT. This paper follows a systematic approach for reviewing compendium of literature to explore the current research in this field. It has been identified smart devices as the primary objects interconnected in the network of loT, having an essential role in this paradigm. The developed concept for defining smart device is based on three main features, namely context-awareness, autonomy and device connectivity. Other features such as mobility and userinteraction were highly mentioned in the literature, but were not considered because of the nature of the loT as a network mainly oriented to device-to-device connectivity whether they are mobile or not and whether they interact with people or not. What emerges from this paper is a concept which can be used to homogenise the terminology used on further research in the Field of digitalisation and smart technologies.
\end{abstract}

Keywords: Smart devices, Internet of things, Mobile devices, Digitalisation, Smart technologies

\section{Introduction}

In 2011 Cisco predicted that 50 billion of Things would be connected to the Internet by 2020 (Evans, 2011). On the other hand, more recent investigations show that 25 billion devices will be connected to the internet by 2020 and those connections aim at facilitating the process of autonomous intelligent decision making (Gartner, 2014). No matter which prediction is right the main highlight is that smart things will be several times more than the estimated world population.

The IoT is proliferating across all sectors, creating opportunities and becoming a competitive marketplace weapon as the focus of primary benefits, shifts from both internal and external improvements of the worldwide industries (Gartner, 2016). Sectors benefitted from

* Correspondence: m.a.silveriofernandez@wlv.ac.uk

Faculty of Science and Engineering, University of Wolverhampton, Wulfruna Street, Wolverhampton WV1 1LY, UK

Springer Open the IoT are: transportation, smart city, smart domotics, smart health, e-governance, assisted living, e-education, retail, logistics, agriculture, automation, industrial manufacturing, process management, among others (Gubbi, Buyya, Marusic, \& Palaniswami, 2013) and (Miorandi, Sicari, De Pellegrini, \& Chlamtac, 2012).

There are many ways to define the IoT, some popular definitions are:

- "a dynamic global network infrastructure with selfconfiguring capabilities based on standard and interoperable communication protocols where physical and virtual 'Things' have identities, physical attributes, and virtual personalities and use intelligent interfaces, and are seamlessly integrated into the information network" (Van Kranenburg, 2008).

- "Things having identities and virtual personalities operating in smart spaces using intelligent interfaces 
to connect and communicate within social, environmental, and user contexts" (INFSO, 2008).

(Lopez, Rios, Bao, \& Wang, 2017) established three main components required for the IoT namely Smart things, network infrastructure and backend servers (see Fig. 1). This simplified architecture describes the essence behind the paradigm of the IoT. The Smart devices seen Fig. 1 are designed to interact both with users and other devices connected to the network, some of these devices might not even require interacting directly with users.

There is a broad range for the objects or "things" in the IoT, some of these objects can get different names in the literature, such as smart devices, mobile devices, smart things or smart objects. Smart devices are considered objects capable of communication and computation which range from simple sensor nodes to home appliances and smartphones (Stojkoska \& Trivodaliev, 2017). This author also considers smart devices as the objects present in the network of the IoT.

The devices in the IoT should have the capability to dynamically adapt to the changing contexts and take actions based on their operating conditions; they should be self-configuring and interoperable, having unique identities and being able to communicate and exchange data with other devices and systems (Ray, 2016). Therefore, smart device should be context-aware and have network connectivity.

Currently, in the literature, different terms are found for what this paper calls smart devices. Lo, Yu and Tseng (2014) used the term smart device, whereas İlhan, Yıldız, \& Kayrak (2016) used the term smart mobile device. The term mobile devices is also used by some authors, such as Lau, et al. (2017), Khan \& Khan (2017) and Furthmüller \& Waldhorst (2012). Azhar \& Cox (2015) uses the terms "mobile tools", "mobile technologies" and "mobile devices" for devices that allow workers to get instant access to project documents, plans and specifications. Azhar
\& Cox (2015) addresses tablets, cloud technologies, Radio Frequency Identification Tag and wearable devices as mobile technologies when tablets, smartphones and wearables are devices that implement various mobile technologies. This misconception is led by the lack of a clear concept of smart device.

This paper intends the define a clear and scalable concept of Smart device, which researchers around the globe can use for further research. The review methodology is described in Section 3, findings are explained in section 4 , and the conclusions are discussed in section 5 .

\section{Justification}

Nowadays the paradigm of Industry 4.0 aims at introducing a new level of organisation and control within the current industry, thus taking the last industrial revolution to a new level of efficiency. Figure 2 shows the four industrial revolutions and locates the Industry 4.0 within a chronological context. Each industrial revolution was separated by a hundred years. Differently, the industry 4 . 0 comes after only half a century. The term Industry 4.0 is regarded as a fourth industrial revolution which defines a new level of organisation and control over the entire value chain of the life cycle of products Rüßmann et al. (2015). The central objective of Industry 4.0 is fulfilling individual customer needs which affect areas such as management, research and development, manufacturing, utilisation and recycling of products.

One of the key players in this revolution is the IoT, which attempts to collect and analyse data and be part of the core process of all industries. According to Lee, Kao \& Yang (2014) The industry 4.0 relies on the IoT for converting regular machines to self-aware and selflearning machines, hence improving their overall performance and maintenance management with the surrounding interaction.

Industry 4.0 proposes a significant change in how things work in the Built environment, but there is also

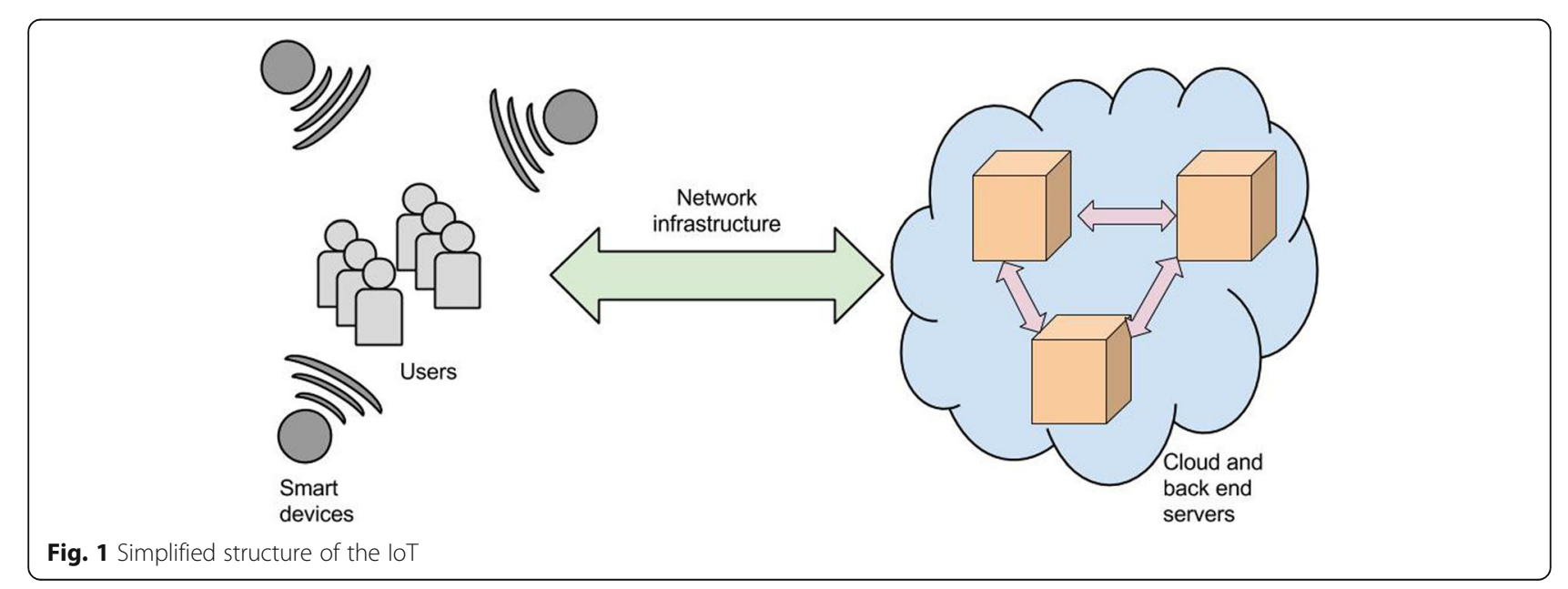






Fig. 2 Four industrial revolutions

the natural environment which has no or little human intervention (for example, the rural sites along train tracks which interconnect cities). The IoT can also be a valuable tool for gathering relevant data for different industries in the Built and natural environment.

In order to help with this embedment of the IoT into the different industries on a worldwide level, several investigations have already contributed with frameworks and toolkits for development of Smart cities through the implementation of the IoT. Some examples are:

- An information framework for creating smart city through the implementation the Internet of Things (Jin et al., 2014).

- Building a Framework for Internet of Things and Cloud Computing (Anon et al., 2014).

Stojkoska \& Trivodaliev (2017) highlights Smart devices as the core devices present in the IoT hence when developing any research or business project related to the IoT the following question arises: What is a smart device?

At the moment of performing this study such question was not answered. The industry 4.0 and any project related to the IoT need to define a dynamic list with a finite number of devices which can be considered as smart. This study will offer clarity and transparency between technology consultants, researchers and companies from all industries which intend to incorporate the paradigm of the IoT.

\section{Review methodology}

This study is aimed at exploring the key features that are directly or indirectly related to smart devices across the literature for subsequently developing a scalable concept of Smart device. This section presents the methodology used to select the most appropriate research publications covering the topic of smart devices.
This paper follows a systematic approach for reviewing compendium of literature to explore the current research in this field. The search for peer-reviewed journal articles has been done via databases, subsequently, this allowed to perform a literature review. A literature review is a systematic and reproducible method for identifying and synthesising the existing body of recorded work generated by researchers or scholars (Fink, 2013). It provides a summary of themes and issues in a specific research field.

The literature was searched using the online service Google Scholar and Science Direct. The main advantages of these services are ease of use and broader universe of cited and citing items (Franceschet, 2010).

\section{Selection criteria}

Stojkoska and Trivodaliev (2017) highlights Smart devices as the core devices present in the IoT. On the other hand, Lanotte and Merro (2018) mention both smart devices and mobile devices. Bisio et al. (2018) mentions only mobile devices as the devices present in the IoT. Although there is a lack of consensus between which term is the right one to be used when referring to the IoT, the etymologic meaning of these term associates the term "mobile devices" to devices with a high degree of mobility, whereas the term "smart device" implies certain level of embedded cleverness in the device. Based on the inherent characteristics of these terms this paper chooses the term Smart device as the name for the objects present in the IoT, thus agreeing with Stojkoska and Trivodaliev (2017). Nevertheless, according to the Google's web search trends presented in Fig. 4, the term "mobile device" shows a higher popularity for when compared with the term "smart device", this encourages the utilisation of this keyword in the filters of the inclusion criteria implemented in this research. Subsequently, both keywords "smart device" and "mobile device" were selected and independent searches for peer-reviewed journal articles has been done via databases. 
The Google trend data presented in Figs. 3 and 4 is adjusted and proportionate to the time and location of the query. Each data point is divided by the total searches of the geography and time range it represents, to compare relative popularity. Otherwise places with the most search volume always be ranked highest. The resulting numbers are then scaled on the Y-axis from 0 to 100 based on a topic's proportion to all searches on all topics.

As can be seen in Fig. 3, from the year 2012 there was an relevant growth in the trends of web search popularity for the term "Internet of Things", consequently, this study adjusted the selection criteria to survey journal papers from the year 2012. In terms of selecting research publications prior 2012, although there are publications, this does not mean adding them to the data collection would enhance the quality of the output of this research. The concept of the IoT has been quickly evolving in latest years in it is the intend of this study to capture the current features perceived in smart devices in the current research community.

In summary, the selection criteria implemented in this study was fundamentally based on Journal papers published from 2012 to June 2017. The inclusion criteria of papers in this time range is the appearance of any of the selected keywords in the title of the paper. The selected keywords were: "Internet of Things", "Smart device" and "Mobile device".

\section{Data analysis}

Thirty publications were selected from the searches based on the keyword "mobile devices" and Twenty from the keyword "smart devices".

Following the guidelines of White \& Marsh (2006) a systematic content analysis was implemented to create themes for the capabilities of smart devices and mobile devices perceived in the analysed papers as well as other keywords utilised by authors for referring to smart devices. Once these themes were identified they were analysed and utilised for the elaboration of a new concept for the term "smart device".

\section{Findings and discussion}

\section{Terminology used in the literature}

The literature review showed an inconsistent terminology, many authors used the term "mobile device" for addressing smartphones, tablets and wearables. Other authors use the term "smart device" to referring to the same devices. Table 1 shows the terms used in the literature for smart devices based on the keyword used for searching the databases.

\section{Key features of smart devices}

A systematic content analysis revealed distinct themes which describe the key capabilities of the devices addressed by the reviewed papers. Tables 2 and 3 show the selected peer-reviewed journal articles selected in the review and their mention of each of the key features exposed by the content analysis. The number of mentions of each feature is used as a quantitative parameter for measuring the relevance of the features discovered in the literatures.

The key features that authors in the literature allocate to smart devices were grouped in the following terms: Autonomy, connectivity, context-awareness, User-interaction, mobility and data storage. Based on the search results obtained from the keywords "smart device" and "mobile device" the key features shown in Tables 2 and 3 can be sorted by the amount of mentions in the literature. Tables 4 and 5 shows the key features of the keywords "smart device" and "mobile device" respectively. As can be observed in both cases, connectivity and user-interaction both have more than a $50 \%$ of mentions.

The feature "mobility" comes mainly from the search performed with the keyword "mobile device", authors particularly assume there is mobility or portability when using the term mobile devices, which is not always the case for smart device. Mobility and user-interaction are not considered key features as in doing so we would contradict some of the key principles of the IoT, which establish that any "thing" can be connected, whether it is mobile or not and whether it interacts with people or

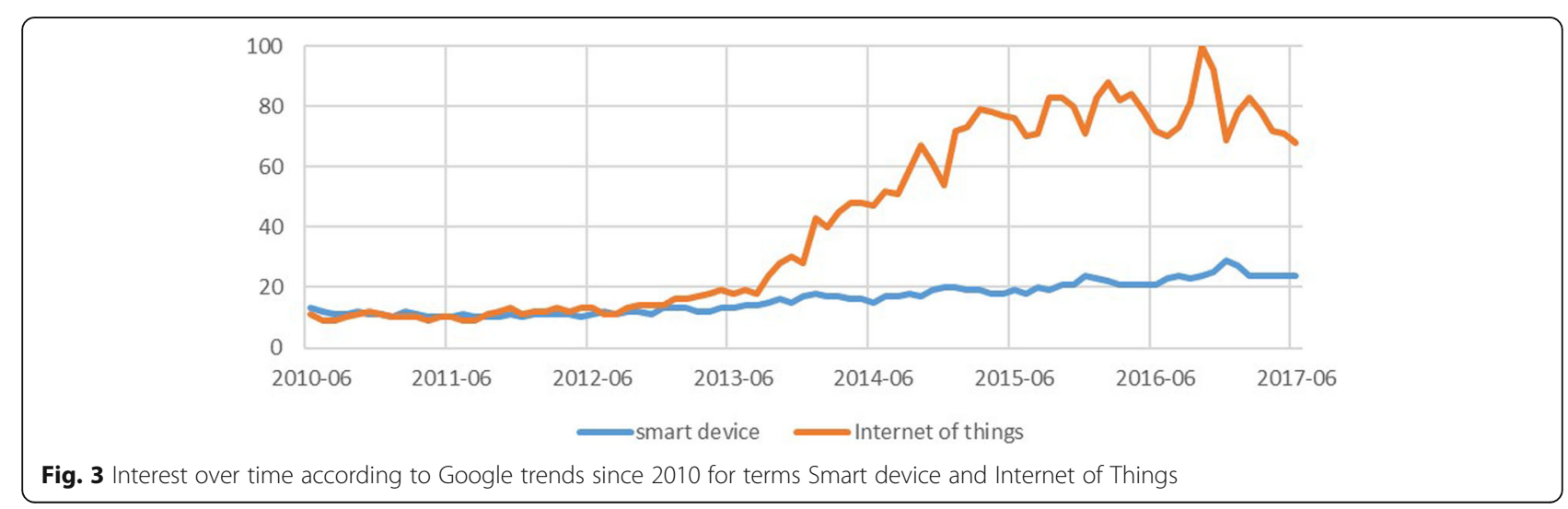




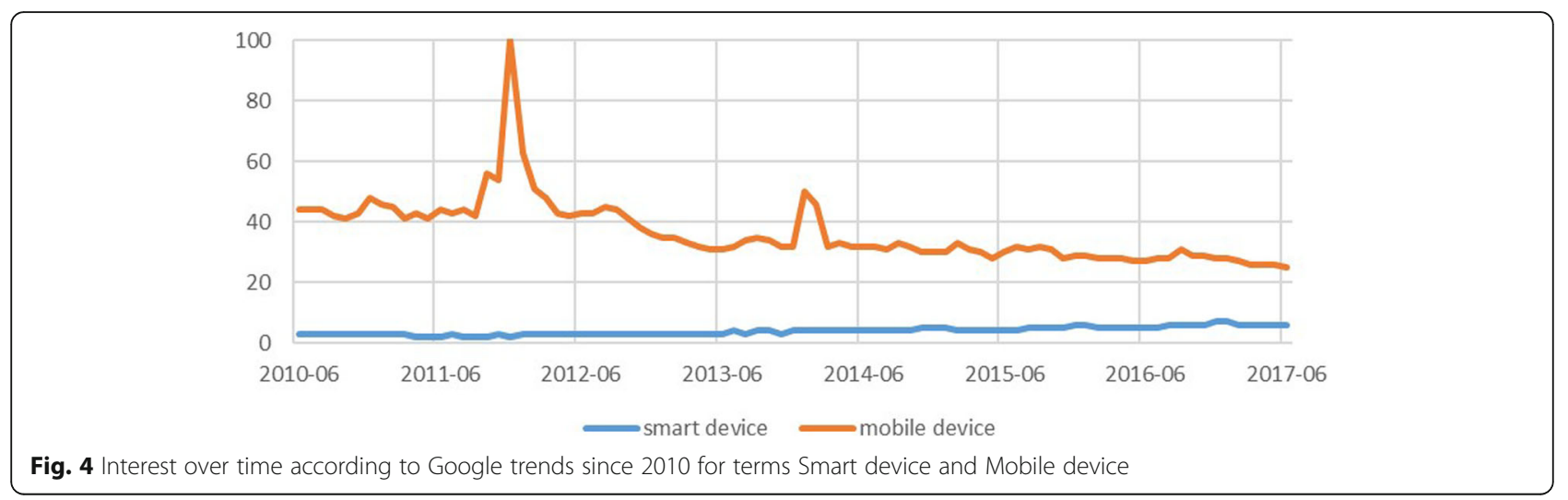

not (Miller, 2015). In fact, one of the core ideas of the IoT is the that devices interact with other devices, not necessarily people; hence the name "Internet of Things", an Internet designed for things, not people. Regarding data storage, although it represents an important capability, it is embedded within other functionalities such as autonomy, context-awareness and connectivity. Therefore, it is not considered as one of the key features for a device to become "smart"; instead this paper considers data-storage as an imbedded attribute inherently required by a device in order to adopt a higher set of features.

Ultimately, the key features considered by this study for a device to become "Smart" are connectivity, autonomy and context-awareness. Being connectivity the most relevant based on the amount of mentions obtained from the literature. The following sections describe in more detail the key features found in the literature.

\section{Autonomy}

The main idea behind autonomy consists of devices performing tasks autonomously without the direct command of the user. From the analysis obtained from the keyword "Smart device" several references to smart devices were denoting autonomous performance of

Table 1 Term used for referring to smart devices in the literature

\begin{tabular}{ll}
\hline From keyword "Smart device" & From keyword "Mobile device" \\
\hline Smart green IT device & Mobile communication device \\
Smart metering device & Mobile computing device \\
Mobile smart device & Hand-held device \\
Smart mobile device & Mobile hand-held device \\
Smart objects & Mobile Internet device \\
Smart sensor-equipped device & Mobile IT device \\
Smart terminal device & Mobile media device \\
Smart wearable device & Mobile network device \\
Tablet smart device & Mobile smart device \\
\hline
\end{tabular}

tasks. For example, Zhang, et al. (2013) explored the factors that play important roles in multitasking scenarios, this requires from smart phones to have certain processing capacity and to perform tasks on the background. In addition, Gans, Alberini, \& Longo (2013) and Schleich, Faure, \& Klobasa (2017) intended to use smart devices as "smart" meters or advanced meters to measure information through sensors and send it through a network autonomously. The term Smart device is also used by Najjar \& Amer (2016) for a control system utilised in engine cars this if founded on the idea of autonomous performance of tasks.

From the analysis obtained from the keyword "Mobile device" various publications refer to mobile devices as tools that can process information autonomously. Vazquez-Fernandez \& Gonzalez-Jimenez (2016) discussed autonomous biometric data processing within mobile devices for face recognition systems. Also, Sung, Chang \& Yang (2015) mentions the utilisation of mobile devices for asynchronous tasks.

\section{Connectivity}

The concept of connectivity in smart devices refers to establishing a connection to a network of any size; Sometimes the main purpose might be gaining internet access, other times it might be sharing information with other devices on the network. The key factor for identifying that an author considers that a smart device has internet access is either when network connectivity is explicitly mentioned or when an activity that requires network connectivity is addressed. For example, Harwood, Dooley, Scott, \& Joiner (2014) states that high internet use is something common on smart devices, this is a direct statement about the utilisation of smart devices for internet access which requires network connectivity. On the other hand, Khan, Shrestha, Wahid, \& Babyn (2015) mentions direct wireless interfacing and full-duplex communication between devices, this statement is a bit more indirect but at the same time assumes that smart devices have network connectivity. 
Table 2 Matrix between key features found for keyword "Smart device" and reviewed Journal papers

\begin{tabular}{|c|c|c|c|c|c|c|}
\hline No. & Reference & Connectivity & User-interaction & Autonomy & Context-awareness & Data-storage \\
\hline 1 & Medeiros, Holguín, Shin, \& Park, 2010 & & & $x$ & & \\
\hline 2 & Meyer, Yeh, \& Tsai, 2012 & & $x$ & & & \\
\hline 3 & Gans, Alberini, \& Longo, 2013 & & & $x$ & & $x$ \\
\hline 4 & Godwin et al., 2013 & & $x$ & & $x$ & \\
\hline 5 & Zhang et al., 2013 & $x$ & & $x$ & $x$ & \\
\hline 6 & Harwood, Dooley, Scott, \& Joiner, 2014 & $x$ & $x$ & & & \\
\hline 7 & Husnjak, Perakovic, \& Jovovic, 2014 & & $x$ & & $x$ & \\
\hline 8 & Lo, Yu, \& Tseng, 2014 & & & $x$ & & \\
\hline 9 & Chena \&Chena, 2015 & $x$ & $x$ & & & $x$ \\
\hline 10 & Khan, Shrestha, Wahid, \& Babyn, 2015 & $x$ & & $x$ & & \\
\hline 11 & Koo, Chung, \& Nam, 2015 & & & & $x$ & \\
\hline 12 & Azad et al., 2016 & $x$ & & & & $x$ \\
\hline 13 & Illhan, Yıldız, \& Kayrak, 2016 & $x$ & & $x$ & $x$ & $x$ \\
\hline 14 & Muhammad \& Devi, 2016 & $x$ & $x$ & & & \\
\hline 15 & Najjar \& Amer, 2016 & $x$ & & $x$ & & \\
\hline 16 & Vorderer, Krömer, \& Schneider, 2016 & $x$ & $x$ & & & \\
\hline 17 & Cheng \& Mitomo, 2017 & $x$ & $x$ & & & \\
\hline 18 & Li, Chen, \& Lu, 2017 & & & & & \\
\hline 19 & Sánchez-Arias, González García, \& Pelayo G-Bustelo, 2017 & $x$ & $x$ & & & \\
\hline \multirow[t]{2}{*}{20} & Schleich, Faure, \& Klobasa, 2017 & & & $x$ & & \\
\hline & & 11 & 9 & 8 & 5 & 4 \\
\hline
\end{tabular}

One of the most explicit reference to connectivity was obtained from Cheng \& Mitomo (2017) which explains that what makes these devices "smart" is their wireless communication capability, which enables them to connect to the internet.

\section{Context-awareness}

The main idea behind context-awareness is the ability of smart devices to perceive information from the environment through sensors such as camera, accelerometer, microphone and Global Positioning System (GPS). The information gathered through sensors can then be utilised to make autonomous decisions or to provide direct assistance to the user.

The analysis was oriented to detect any mention of the utilisation of sensors with either "smart devices" or "mobile devices" keywords. Godwin, et al., (2013) and Zhang et al., (2013) mentioned the utilisation of smart devices for photography or video recording, whereas Husnjak, Perakovic \& Jovovic (2014) addressed the implementation of smart devices for human voice recognition.

The literature obtained from the keyword "mobile device" mentions the utilisation of GPS, accelerometer, microphone and camera. Furthmüller \& Waldhorst (2012) explained that mobile devices ffer a set of resources in which we find sensors like GPS and accelerometer. Maryn,
Ysenbaert, Zarowski, \& Vanspauwen (2017) mentioned various built-in sensors carried by mobile devices such as a microphone, camera, GPS, accelerometer and light sensor.

\section{User-interaction}

The literature suggest that Smart devices are designed to interact with users, whether it is a smartphone or smart bracelet, there is certain level of interaction with a user in which the device either collects or provide data to the user. In this study the main criteria for the identification of interaction with users is the mention of consumer, user, or any activity which requires a person. For example, Harwood, Dooley, Scott, \& Joiner (2014) explained that a smart device allows users to ubiquitously conduct activities such as gaming, internet-browsing, texting, emailing, social networking and phone calls, all these activities are specifically designed for a user.

Despite the inclination of Smart devices being used by users, Stojkoska \& Trivodaliev (2017) states that smart devices are the objects presents in the IoT. In addition, Miller (2015) establishes that the IoT is all about the interconnection of devices, to the point where some devices might never interact directly with users, whereas instead they interact with other devices. Considering the theory behind the IoT this study does not consider user-interaction as a key feature for a device to become "Smart". 
Table 3 Matrix between key features found for keyword "Mobile device" and reviewed Journal papers

\begin{tabular}{|c|c|c|c|c|c|c|}
\hline No. & Reference & Connectivity & User-interaction & Autonomy & Context-awareness & Mobility \\
\hline 1 & Mao, Xiao, Shi, \& Lu, 2012 & $x$ & $x$ & & & \\
\hline 2 & Ehmen et al., 2012 & & & $x$ & & \\
\hline 3 & Furthmuller and Waldhorst, 2012 & $x$ & $x$ & & $x$ & \\
\hline 4 & Son, Park, Kim, \& Chou, 2012 & $x$ & $x$ & & & $x$ \\
\hline 5 & Almuairfi, Veeraraghavan, \& Chilamkurti, 2013 & $x$ & & & & \\
\hline 6 & Zhong, 2013 & $x$ & $x$ & & & \\
\hline 7 & Kobus, Rietveld, \& Van Ommeren, 2013 & & $x$ & & & \\
\hline 8 & Melo, Bessa, Debattista, \& Chalmers, 2014 & & $x$ & & & \\
\hline 9 & Richart \& Bryant, 2014 & & $x$ & & & \\
\hline 10 & Wu, 2014 & $x$ & $x$ & & & \\
\hline 11 & Suarez et al., 2015 & & $x$ & & & \\
\hline 12 & Kang et al., 2015 & $x$ & & & & \\
\hline 13 & Sung, Chang, \& Yang, 2015 & $x$ & $x$ & $x$ & $x$ & $x$ \\
\hline 14 & Sattineni \& Schmidt, 2015 & $x$ & $x$ & & & $x$ \\
\hline 15 & Markelj \& Bernik, 2015 & $x$ & & & & \\
\hline 16 & Dahri, Gong, \& Loewen, 2016 & $x$ & $x$ & & & \\
\hline 17 & Mathew et al., 2016 & & $x$ & & & \\
\hline 18 & Moreira, Ferreira, Santos, \& Durao, 2016 & $x$ & $x$ & & & $x$ \\
\hline 19 & Vazquez-Fernandez \& Gonzalez-Jimenez, 2016 & $x$ & & $x$ & & \\
\hline 20 & Mascetti et al., 2016 & & $x$ & & $x$ & \\
\hline 21 & Tawalbeh \& Eardley, 2016 & $x$ & & & & \\
\hline 22 & Roberto, Lima, \& Teichrieb, 2016 & $x$ & $x$ & $x$ & $x$ & \\
\hline 23 & Rodríguez, Riaza, \& Gomez, 2017 & & $x$ & & & \\
\hline 24 & Lau et al., 2017 & $x$ & $x$ & & & \\
\hline 25 & Khan and Khan, 2017 & $x$ & & & $x$ & \\
\hline 26 & Suki and Suki, 2017 & $x$ & $x$ & & & \\
\hline 27 & Forehand, Miller, \& Carter, 2017 & $x$ & & & & $x$ \\
\hline 28 & Maryn, Ysenbaert, Zarowski, \& Vanspauwen, 2017 & & & & $x$ & \\
\hline 29 & Xie, Szeto, \& Dai, 2017 & $x$ & $x$ & & & \\
\hline \multirow[t]{2}{*}{30} & Stojanovic et al., 2017 & & $x$ & $x$ & $x$ & $x$ \\
\hline & & 20 & 21 & 5 & 7 & 6 \\
\hline
\end{tabular}

\section{Mobility - Portability}

The aspect of mobility and portability was found specifically for the keyword "mobile device". Some authors refer to portability or mobility as one of the main advantages of mobile devices. As per Moreira, Ferreira, Santos,
\& Duro (2016), portability is a key aspect of interest for practitioners in the field of education for mobile learning applications. Also, Sattineni \& Schmidt (2015) mentioned how big companies like Apple and Microsoft have designed tablets to handle and process everything a

Table 4 Key features of "smart device" sorted by mentions in literature

\begin{tabular}{llll}
\hline Feature & Mentions in literature (out of 20 journal papers) & Percentage \\
\hline Connectivity & 11 & $55.0 \%$ & $45.0 \%$ \\
User-interaction & 9 & $40.0 \%$ & $25.0 \%$ \\
Autonomy & 8 & $20.0 \%$ \\
Context-awareness & 5 & 4 & 2 \\
Data storage & 4 & & $2.0 \%$ \\
\hline
\end{tabular}


Table $\mathbf{5}$ Key features of "mobile device" sorted by mentions in literature

\begin{tabular}{llll}
\hline Feature & Mentions in literature (out of 30 Journal papers) & Percentage \\
\hline User-interaction & 21 & $70.0 \%$ & $66.7 \%$ \\
Connectivity & 20 & 7 & $23.3 \%$ \\
Context-awareness & 6 & $20.0 \%$ \\
Mobility & 5 & $16.7 \%$ \\
Autonomy & & & \\
\hline
\end{tabular}

normal full-size computer can along with the bonus of mobility.

Although mobility is very characteristic feature of Smartphones, tablets and smart watches, this feature does not apply to every smart device. One example is a Smart board, a board which is not mobile but is can be considered a smart device. Malkawi (2017) presents a smart board as an electronic white board connected to a computer and data show which can be used for distinct users as a typical white board as well as to open applications, navigate the web, use drawing tools, visualising text, images, augio, video and creating virtual forms or shapes.

The definition of Smart devices goes beyond Smartphones and tablets, the paradigm of IoT says that anything can be connected and smart which means that objects with low mobility should also be included into this group. For this reason, mobility is not considered as a key feature for a device to become Smart.

\section{What is a smart device?}

The key features found in smart devices through the review of the literature have been grouped into three main categories namely, context-awareness, device connectivity and autonomy. The literature also suggests "user interaction" and "mobility-portability" as key features to consider, but at the same time the theory behind the IoT establishes that this paradigm is about things interacting with other things.

Most of the authors when referring to "mobile devices" envision smartphones, tablets and wearables, by doing so they are addressing the same devices that other authors call "smart devices". This paper chooses not to include the feature of mobility to the concept of smart device hence it would then discard all devices which comply with the main categories but are not mobile. Instead, the term mobile smart device can be used.

Considering the main features of smart devices, this paper proposes the following definition:

A smart device is a context-aware electronic device capable of performing autonomous computing and connecting to other devices wire or wirelessly for data exchange.

This concept encompasses a dynamic but finite number of devices which can integrate in a network and participate in the paradigm of the IoT. section 4.1 describes other terms which have been added to the term "smart device" to describe specific features of these devices. Such terms can be: metering, wearable, hand-held, etc. Consequently, we can refer to smart devices which interact with users by using the term "smart wearable device" or "smart hand-held device". Nevertheless, Smart device is proposed by this study as the core term to be used for the devices present in the IoT.

\section{Conclusions}

This paper addresses the concept of smart device within the paradigm of the IoT. This concept has been under development for the last decade, and due to the growing complexity of these devices and the fast changing and evolving research community, there was a need for a clear definition conceptualisation of this term. The concept developed in this paper is modular and scalable, this means that new key features might be added depending on the changing features of the global market and state of technology.

This study proposes three pillars or key features that make a device or object "smart", namely Autonomy, context-awareness and connectivity. It can be inferred that almost any device or object can become smart by adding these features. For example, if a chair gets a sensor (context-awareness) for detecting when, then it processes that information (autonomous computing) and sends it through a network (device connectivity), in that moment we can call that chair "Smart". Moreover, by using a similar approach with other devices, we can easily implement the paradigm of IoT in the industry and homes.

User-interaction was one of the features with higher appearance (see Tables 2 and 3) in the review, as authors consider smart or mobile devices as devices designed to interact with users. This generates a contradiction between the core theory of the IoT. According to Stojkoska \& Trivodaliev (2017) and Miller (2015) the IoT is designed for objects to interact between them, and although humans play a role in this network, some devices might only interact with other devices.

Miller (2015, page 9) states:

"Most of the things connected to the IoT are actually simple devices that are often referred as smart devices. The devices themselves aren't necessarily smart in and of 
themselves, but become smart when joined together with other connected devices".

This sentence highlights smart devices as the key element of the IoT which need to interact with other devices in order to become "smart". Therefore, a device in isolation is not smart, it needs to interact with other devices. Although the ultimate purpose of the IoT might be to provide services to final users the emphasis in the interaction of a smart device is on the interaction with other devices not people.

This study will offer clarity and transparency between technology consultants, researchers and companies from all industries which intend to incorporate the paradigm of the IoT. The concept offered in this research will help to build a set of finite smart devices which companies can use based on their company size, company type and project type. As mentioned by Lee, Kao \& Yang (2014) the industry 4.0 relies on the IoT for improving its overall performance and maintenance management with the surrounding interaction, consequently a clear definition of smart device serves as a tool to ease the future development of frameworks for executing the IoT and the industry 4.0.

\section{Abbreviations}

GPS: Global Positioning System; loT: Internet of Things

\section{Authors' contributions}

All the authors contributed to the work presented in this paper. The corresponding author searched the databases, selected the articles, reviewed and analysed the literature and prepared the manuscript. Second and third author supervised the overall review, and edited the manuscript. All authors read and approved the final manuscript.

\section{Competing interests}

The authors declare that they have no competing interests.

\section{Publisher's Note}

Springer Nature remains neutral with regard to jurisdictional claims in published maps and institutional affiliations.

Received: 18 December 2017 Accepted: 23 April 2018

Published online: 09 May 2018

\section{References}

Almuairfi, S, Veeraraghavan, P, Chilamkurti, N. (2013). A novel image-based implicit password authentication system (IPAS) for mobile and non-mobile devices. Mathematical and Computer Modelling, 58(1), 108-116.

Anon, F., Navarathinarasah, V., Hoang, M., \& Lung, C. (2014). Building a framework for internet of things and cloud computing. Paper presented at the Internet of Things (iThings), 2014 IEEE International Conference on, and Green Computing and Communications (GreenCom), IEEE and Cyber, Physical and Social Computing (CPSCOm), IEEE, pp. 132-139.

Azad, S., Rahman, M., Ranak, M. N., Ruhee, B. K., Nisa, N. N., Kabir, N.,. .. Zain, J. M. (2016). VAP code: A secure graphical password for smart devices. Computers \& Electrical Engineering,

Azhar, S., \& Cox, A. J. (2015). Impact of mobile tools and technologies on jobsite operations. 51st ASC Annual International Conference Proceedings,

Bisio, I., Garibotto, C., Lavagetto, F., Sciarrone, A., Zappatore, S. (2018). Unauthorized Amateur UAV Detection Based on WiFi Statistical Fingerprint Analysis. IEEE Communications Magazine, 56(4), 106-111.
Chena, ZX, \& Chena, CC. (2015). The intention of using smart device messages as parent-teacher communication from the view of parents. Procedia Manufacturing, 3, 5617-5623.

Cheng, JW, \& Mitomo, H. (2017). The underlying factors of the perceived usefulness of using smart wearable devices for disaster applications. Telematics and Informatics, 34(2), 528-539.

Dahri, K, Gong, Y, Loewen, P. (2016). A quantitative and qualitative assessment of the utilization of mobile computing devices by clinical pharmacists. Health Policy and Technology, 5(3), 285-290.

Ehmen, H, Haesner, M, Steinke, I, Dorn, M, Gövercin, M, Steinhagen-Thiessen, E. (2012). Comparison of four different mobile devices for measuring heart rate and ECG with respect to aspects of usability and acceptance by older people. Applied Ergonomics, 43(3), 582-587.

Evans, D. (2011). The internet of things: How the next evolution of the internet is changing everything. CISCO White Paper, 1(2011), 1-11.

Fink, A (2013). Conducting research literature reviews: From the internet to paper. Sage Publications.

Forehand, JW, Miller, B, Carter, H. (2017). Integrating mobile devices into the nursing classroom. Teaching and Learning in Nursing, 12(1), 50-52.

Franceschet, M. (2010). A comparison of bibliometric indicators for computer science scholars and journals on web of science and google scholar. Scientometrics, 83(1), 243-258.

Furthmüller, J, \& Waldhorst, OP. (2012). Energy-aware resource sharing with mobile devices. Computer Networks, 56(7), 1920-1934. https://doi.org/10. 1016/j.comnet.2012.02.007.

Gans, W, Alberini, A, Longo, A. (2013). Smart meter devices and the effect of feedback on residential electricity consumption: Evidence from a natural experiment in Northern Ireland. Energy Economics, 36, 729-743. https://doi. org/10.1016/j.eneco.2012.11.022.

Gartner. (2014). Gartner says 4.9 billion connected "things" will be in use in 2015. Retrieved from http://www.gartner.com/newsroom/id/2905717

Gartner. (2016). Measuring the strategic value of the internet of things for industries. Retrieved from https://www.gartner.com/doc/3299317

Godwin, ZR, Bockhold, JC, Webster, L, Falwell, S, Bomze, L, Tran, NK. (2013). Development of novel smart device based application for serial wound imaging and management. Burns : Journal of the International Society for Burn Injuries, 39(7), 1395. https://doi.org/10.1016/j.burns.2013.03.021.

Gubbi, J, Buyya, R, Marusic, S, Palaniswami, M. (2013). Internet of things (IoT): A vision, architectural elements, and future directions. Future Generation Computer Systems, 29(7), 1645-1660.

Harwood, J, Dooley, JJ, Scott, AJ, Joiner, R. (2014). Constantly connected - the effects of smart-devices on mental health. Computers in Human Behavior, 34, 267. https://doi.org/10.1016/j.chb.2014.02.006

Husnjak, S, Perakovic, D, Jovovic, I. (2014). Possibilities of using speech recognition systems of smart terminal devices in traffic environment. Procedia Engineering, 69, 778-787. https://doi.org/10.1016/j.proeng.2014.03.054.

Illhan, I, Yıldız, I, Kayrak, M. (2016). Development of a wireless blood pressure measuring device with smart mobile device. Computer Methods and Programs in Biomedicine, 125, 94-102. https://doi.org/10. 1016/j.cmpb.2015.11.003.

INFSO, D (2008). Networked enterprise \& RFID INFSO G. 2 micro \& nanosystems, in cooperation with the working group RFID of the ETP EPOSS, internet of things in 2020, Roadmap for the future [R]. Berlin: Information Society and Media, Tech. Rep.

Jin, J, Gubbi, J, Marusic, S, Palaniswami, M. (2014). An information framework for creating a smart city through internet of things. IEEE Internet of Things Journal, 1(2), 112-121.

Kang, L., Weng, M., Jheng, C., Tseng, C., Ramesh, S. K., Gureja, A.». . Yeh, C. (2015). Content-aware image retargeting for image display on foldable mobile devices. Procedia Computer Science, 56, 104-110.

Khan, R, \& Khan, SU. (2017). Energy saving through intelligent coordination among daily used fixed and mobile devices. Sustainable Computing: Informatics and Systems, 14, 43-57.

Khan, TH, Shrestha, R, Wahid, KA, Babyn, P. (2015). Design of a smart-device and FPGA based wireless capsule endoscopic system. Sensors and Actuators A: Physical, 221, 77-87. https://doi.org/10.1016/j.sna.2014.10.033.

Kobus, MB, Rietveld, P, Van Ommeren, JN. (2013). Ownership versus oncampus use of mobile IT devices by university students. Computers \& Education, 68, 29-41.

Koo, C, Chung, N, Nam, K. (2015). Assessing the impact of intrinsic and extrinsic motivators on smart green IT device use: Reference group perspectives. International Journal of Information Management, 35(1), 64-79. 
Lanotte, R, \& Merro, M. (2018). A semantic theory of the internet of things. Information and Computation.

Lau, KP, Chiu, DK, Ho, KK, Lo, P, See-To, EW. (2017). Educational usage of mobile devices: Differences between postgraduate and undergraduate students. The Journal of Academic Librarianship, 43(3), 201-208.

Lee, J, Kao, H, Yang, S. (2014). Service innovation and smart analytics for industry 4.0 and big data environment. Procedia Cirp, 16, 3-8.

Li, W, Chen, X, Lu, S. (2017). Content synchronization using device-to-device communication in smart cities. Computer Networks, 120, 170-185.

Lo, S, Yu, T, Tseng, C. (2014). A remote control and media-sharing system using smart devices. Journal of Systems Architecture, 60(8), 671. https://doi.org/10. 1016/j.sysarc.2014.04.005.

Lopez, J, Rios, R, Bao, F, Wang, G. (2017). Evolving privacy: From sensors to the internet of things. Future Generation Computer Systems.

Malkawi, NAM. (2017). The effect of using smart board on the achievement of tenth grade students in english language and on verbal interaction during teaching in public schools. International Research in Education, 5(1), 197-208.

Mao, H, Xiao, N, Shi, W, Lu, Y. (2012). Wukong: A cloud-oriented file service for mobile internet devices. Journal of Parallel and Distributed Computing, 72(2), 171-184

Markelj, B, \& Bernik, I. (2015). Safe use of mobile devices arises from knowing the threats. Journal of Information Security and Applications, 20, 84-89.

Maryn, Y, Ysenbaert, F, Zarowski, A, Vanspauwen, R. (2017). Mobile communication devices, ambient noise, and acoustic voice measures. Journal of Voice, 31(2), e23. https://doi.org/10.1016/j.jvoice.2016.07.023.

Mascetti, S, Ahmetovic, D, Gerino, A, Bernareggi, C, Busso, M, Rizzi, A. (2016). Robust traffic lights detection on mobile devices for pedestrians with visual impairment. Computer Vision and Image Understanding, 148, 123-135.

Mathew, JI, Cadnum, JL, Sankar, T, Jencson, AL, Kundrapu, S, Donskey, CJ. (2016). Evaluation of an enclosed ultraviolet-C radiation device for decontamination of mobile handheld devices. American Journal of Infection Control, 44(6), 724-726.

Medeiros, H, Holguín, G, Shin, PJ, Park, J. (2010). A parallel histogram-based particle filter for object tracking on SIMD-based smart cameras. Computer Vision and Image Understanding, 114(11), 1264-1272.

Melo, M, Bessa, M, Debattista, K, Chalmers, A. (2014). Evaluation of HDR video tone mapping for mobile devices. Signal Processing: Image Communication 29(2), 247-256

Meyer, GG, Yeh, Y, Tsai, M. (2012). Smart devices for demand side power consumption management. AASRI Procedia, 2, 216-222.

Miller, M (2015). The internet of things: How smart TVs, smart cars, smart homes, and smart cities are changing the world. London: Pearson Education.

Miorandi, D, Sicari, S, De Pellegrini, F, Chlamtac, I. (2012). Internet of things: Vision, applications and research challenges. Ad Hoc Networks, 10(7), 1497-1516.

Moreira, F, Ferreira, MJ, Santos, CP, Duro, N. (2016). Evolution and use of mobile devices in higher education: A case study in portuguese higher education institutions between 2009/2010 and 2014/2015. Telematics and Informatics.

Muhammad, P, \& Devi, SA. (2016). Hand gesture user interface for smart devices based on mems sensors. Procedia Computer Science, 93, 940-946.

Najjar, YS, \& Amer, MMB. (2016). Using a smart device and neuro-fuzzy control system as a sustainable initiative with green cars. Journal of the Energy Institute, 89(2), 256-263.

Ray, PP. (2016). A survey on internet of things architectures. Journal of King Saud University-Computer and Information Sciences.

Richard, CA, \& Bryant, JE. (2014). Pharmacy student perceptions on the introduction of clinical case studies solved with apple mobile devices into a basic health science laboratory. Currents in Pharmacy Teaching and Learning 6(5), 659-666.

Roberto, R, Lima, JP, Teichrieb, V. (2016). Tracking for mobile devices: A systematic mapping study. Computers \& Graphics, 56, 20-30.

Rodríguez, Al, Riaza, BG, Gómez, MCS. (2017). Collaborative learning and mobile devices: An educational experience in primary education. Computers in Human Behavior, 72, 664-677.

Rüßmann, M, Lorenz, M, Gerbert, P, Waldner, M, Justus, J, Engel, P, et al. (2015). Industry 4.0: The future of productivity and growth in manufacturing industries, (p. 9). Boston Consulting Group. http://www.inovasyon.org/pdf/bcg. perspectives_Industry.4.0_2015.pdf.

Sánchez-Arias, G, García, CG, G-Bustelo, BCP. (2017). Midgar: Study of communications security among smart objects using a platform of heterogeneous devices for the internet of things. Future Generation Computer Systems, 74, 444-466.
Sattineni, A, \& Schmidt, T. (2015). Implementation of mobile devices on jobsites in the construction industry. Procedia Engineering, 123, 488-495.

Schleich, J, Faure, C, Klobasa, M. (2017). Persistence of the effects of providing feedback alongside smart metering devices on household electricity demand. Energy Policy, 107, 225-233.

Son, H, Park, Y, Kim, C, Chou, J. (2012). Toward an understanding of construction professionals' acceptance of mobile computing devices in South Korea: An extension of the technology acceptance model. Automation in Construction, 28, 82-90.

Stojanovic, V, Falconer, RE, Isaacs, J, Blackwood, D, Gilmour, D, Kiezebrink, D, Wilson, J. (2017). Streaming and 3D mapping of AGRI-data on mobile devices. Computers and Electronics in Agriculture, 138, 188-199.

Stojkoska, BLR, \& Trivodaliev, KV. (2017). A review of internet of things for smart home: Challenges and solutions. Journal of Cleaner Production, 140, 1454-1464.

Suarez, JP, Trujillo, A, Santana, JM, de la Calle, M, Gomez-Deck, D. (2015). An efficient terrain level of detail implementation for mobile devices and performance study. Computers, Environment and Urban Systems, 52, 21-33.

Suki, NM, \& Suki, NM. (2017). Flight ticket booking app on mobile devices: Examining the determinants of individual intention to use. Journal of Air Transport Management, 62, 146-154.

Sung, Y, Chang, K, Yang, J. (2015). How effective are mobile devices for language learning? A meta-analysis. Educational Research Review, 16, 68-84.

Tawalbeh, M, \& Eardley, A. (2016). Studying the energy consumption in mobile devices. Procedia Computer Science, 94, 183-189.

Van Kranenburg, R (2008). The internet of things: A critique of ambient technology and the all-seeing network of RFID. Amsterdam: Institute of Network Cultures.

Vazquez-Fernandez, E, \& Gonzalez-Jimenez, D. (2016). Face recognition for authentication on mobile devices. Image and Vision Computing, 55, 31-33. https://doi.org/10.1016/j.imavis.2016.03.018.

Vorderer, P, Krömer, N, Schneider, FM. (2016). Permanently online-permanently connected: Explorations into university students' use of social media and mobile smart devices. Computers in Human Behavior, 63, 694-703.

White, MD, \& Marsh, EE. (2006). Content analysis: A flexible methodology. Library Trends, 55(1), 22-45.

Wu, T. (2014). Using smart mobile devices in social-network-based health education practice: A learning behavior analysis. Nurse Education Today, 34(6), 958-963.

Xie, Y, Szeto, G, Dai, J. (2017). Prevalence and risk factors associated with musculoskeletal complaints among users of mobile handheld devices: A systematic review. Applied Ergonomics, 59, 132-142.

Zhang, Y, Mao, M, Rau, PP, Choe, P, Bela, L, Wang, F. (2013). Exploring factors influencing multitasking interaction with multiple smart devices. Computers in Human Behavior, 29(6), 2579. https://doi.org/10.1016/j.chb.2013.06.042.

Zhong, B. (2013). From smartphones to iPad: Power users' disposition toward mobile media devices. Computers in Human Behavior, 29(4), 1742-1748.

\section{Submit your manuscript to a SpringerOpen ${ }^{\mathcal{O}}$ journal and benefit from:}

- Convenient online submission

- Rigorous peer review

- Open access: articles freely available online

- High visibility within the field

- Retaining the copyright to your article

Submit your next manuscript at $>$ springeropen.com 